\title{
Corpo e moda com glamour: imagens sobre a adolescência
}

\author{
Body and fashion with glam: images about adolescence \\ Luana Ferreira de Souza \\ Universidade Estadual de Campinas, Campinas, São Paulo, Brasil.
}

$\diamond$

\begin{abstract}
Resumo: Este trabalho, resultado da dissertação de mestrado, tem como objetivo analisar, articulado com a construção social do sujeito feminino, as imagens de si das adolescentes que escrevem para uma seção da revista Capricho, a saber: a seção Tudo de Blog. Ponho em análise a construção dessas imagens, observando, sobretudo, quais são as representações e os estereótipos que $o$ ato de tomar a palavra e falar sobre si recuperam no interdiscurso. Esse gesto se justifica pela tentativa de compreender quais são as cristalizações em torno da imagem feminina que subjazem às práticas da adolescência na mídia impressa. $\mathrm{O}$ empreendimento dessas reflexões tem como base o interesse por investigar o quadro teórico-analítico proposto por Maingueneau $(1997,2005,2008)$, Amossy $(2005,2010)$ e Charaudeau (2008) a respeito do ethos discursivo e de sua construção nas práticas sociais acerca do feminino, por meio do discurso midiático, observando, então, a relação imagem de si/feminino
\end{abstract}

Palavras-chave: ethos; adolescência; gênero; Tudo de Blog.

\begin{abstract}
This work, wich is the resulto f a master's dissertation, seeks to analyze - articulated with the social construction of the female subject, the self images of the teenage girls who write for a section of Capricho Magazine, namely: Tudo de Blog. Here I analyze the construction of these images observing, above all, the representations and stereotypes that the act of taking the floor and talking about themselves recover in the interdiscourse. This gesture is justified by the attempt to understand the crystallizations wich are constrcted around the female image and wich underlie the practices of the adolescence in the print media. The work of these reflections is based on the interest to investigate the theoretical-analytical framework proposed by Maingueneau (1997, 2005, 2008), Amossy (2005 and 2010), Charaudeau (2008) regarding the discursive ethos and its construction in the social practices about the feminine by means of the mediatic discourse, then, observing the image relation between oneself/feminine.
\end{abstract}

Keywords: ethos; adolescence; genre; Tudo de Blog.

\section{Considerações iniciais}

Os estudos discursivos têm se mostrado um terreno profícuo de investigações no que concerne à atividade de linguagem. É nessa perspectiva que este trabalho se insere, objetivando investigar a construção das imagens de si, correspondente à noção de ethos, em sua articulação com a construção social do sujeito feminino, das adolescentes que escrevem para uma seção da revista Capricho, a saber: a seção Tudo de Blog, doravante TDB. Dessa maneira, pretendo analisar a construção dessas imagens, observando, sobretudo, quais são as representações e os estereótipos que o ato de tomar a palavra e falar sobre si recuperam no interdiscurso. Esse gesto se justifica pela tentativa de compreender quais são as cristalizações em torno da imagem feminina que subjazem as práticas da adolescência na mídia impressa.

A seção selecionada para análise é o resultado de uma troca entre a revista e suas leitoras que é iniciada nas páginas pessoais - blogs - das adolescentes e apresenta, por meio de uma organização narrativa, o posicionamento das adolescentes diante de um tema escolhido pela revista. Voltando o olhar para a análise das imagens de si das escreventes, busco mostrar como, por meio do gesto de falar de si, de contar sua experiência, as adolescentes 
se valem de um efeito intimista ${ }^{1}$ da enunciação na elaboração da sua argumentação e na construção de sua imagem. Nesse gesto de análise, procuro compreender de que modo são constituídos os discursos em torno do feminino, tendo em vista as discussões acerca das relações de gênero enquanto elemento constitutivo das relações histórico-sociais.

$\mathrm{Na}$ tentativa de compreender como as imagens de si, construídas pelas adolescentes, mesmo com todas as contribuições do movimento feminista e das modificações em torno da imagem do feminino, revelam uma possível naturalização de determinados comportamentos e práticas sociais do que é preciso para "tornar-se mulher", este trabalho promove a articulação dos estudos da linguagem com os estudos sobre gênero, fomentando o debate dessas articulações. $\mathrm{O}$ empreendimento dessas reflexões tem como base o interesse por investigar o quadro teórico-analítico proposto por Amossy (2005, 2010), Maingueneau (1997, 2005, 2008) e Charaudeau (2008) a respeito do ethos discursivo e de sua construção nas práticas sociais acerca do feminino, por meio do discurso midiático, observando, então, a relação imagem de si/feminino.

\section{Olhares sobre o Ethos}

Numa perspectiva aristotélica, o ethos é uma das provas mais importantes que o orador pode utilizar para persuadir o auditório. Aliado ao ethos, Aristóteles propõe ainda o pathos e o logos como provas necessárias à argumentação.

O pathos é entendido, em Aristóteles, como o conjunto de emoções, paixões e sentimentos despertados no auditório através do discurso do orador. O logos diz respeito ao discurso, aos argumentos propriamente ditos utilizados na elocução; seria então a parte lógica, racional da atividade persuasiva. O ethos, por sua vez, é "a imagem de si que o orador constrói em seu discurso para contribuir à eficácia de seu dizer" (AMOSSY, 2010, p.61). “A retórica se concentra, portanto, sobre o si (ethos), sobre um tema $(\log o s)$, portanto, sobre a resposta apropriada, e sobre os outros, isto é o auditório (pathos)"2, afirma Meyer (2009, p. 2).

\footnotetext{
Em linhas gerais, na dissertação, pude observar que ao escreverem sobre si, contarem suas experiências, as adolescentes se valem de um efeito intimista, isto é, um ethos mostrado de intimidade, para, assim, poderem levar o leitor a compartilhar o seu ponto vista. Discuti ainda que, embora os textos da seção sejam apresentados também em forma de narração, há uma visée persuasiva nesses textos, que permite com que as adolescentes compartilhem com os leitores seu posicionamento diante do tema da revista. Acredito, assim, que esse efeito intimista é uma estratégia que permite ocultar o grau de argumentatividade do texto, visto que esse efeito viabiliza uma aproximação das adolescentes com o mundo ético dos leitores, facilitando, assim, a identificação.

2 Minha tradução do francês: "La rhétorique porte donc sur le soi (ethos), sur une question $(\log o s)$, donc la réponse à y apporter, et sur les autres, c'est-à-dire l'auditoire (pathos)"' (MEYER, 2009, p. 2).
}

Dentre essas provas, o ethos é considerado por Aristóteles como o meio mais importante de persuasão. Conforme aponta Amossy (2010, p. 61), “a importância atribuída à pessoa do orador na argumentação é um ponto essencial nas retóricas antigas ${ }^{3 "}$. Nesse sentido, a retomada dos estudos retóricos pelas Ciências Sociais e Humanas ${ }^{4}$, sobretudo nos estudos do discurso, teve sua entrada pela via do ethos. Para o que interessa a este trabalho, a perspectiva discursiva do ethos, vale considerar que a apropriação dessa noção pelos estudos da linguagem, em meados dos anos de 1980, teve como principais expoentes os teóricos Ducrot e Maingueneau.

Retomar uma teoria herdada da Antiguidade Clássica sob a ótica contemporânea, não seria possível sem antes adequá-la considerando seus devidos ajustes. Ao reelaborar a noção de ethos inserindo-a no quadro da Análise do Discurso, Maingueneau (1997) aponta dois deslocamentos necessários para que tal noção seja devidamente inserida nas propostas da teoria. O primeiro deslocamento diz respeito aos efeitos que o orador deseja produzir sobre seu auditório. Para Maingueneau (1997, p. 45), esses efeitos são atributos das formações discursivas, e não do sujeito em si. O segundo deslocamento é que para a obtenção do ethos, na perspectiva da Análise do Discurso francesa, "é preciso recorrer a uma concepção de ethos que não seja transversal à oposição entre o oral e o escrito $5 "$ (MAINGUENEAU, 1997, p. 46).

Nesse sentido, os estudos discursivos têm desenvolvido, entre outras noções, a noção de ethos tomando como base o pensamento aristotélico ao afirmar que o ethos é a construção de uma imagem de si no discurso. Assim, dentro do arcabouço teórico da Análise do Discurso, o estudo do ethos postula que os enunciadores constroem a sua imagem, a partir de uma relação interativa com os co-enunciadores. Segundo Amossy (2005, p.9), "todo ato de tomar a palavra implica uma construção de uma imagem de si”. Não é necessário que o enunciador, ao construir seu ethos no discurso, fale explicitamente das suas qualidades ou defeitos, seus gostos, pois, no discurso, já são lançadas pistas que permitirão ao coenunciador construir a imagem do enunciador.

Dessa maneira, é preciso compreender que toda vez que o sujeito toma a palavra é construída uma imagem de si e do outro. O ethos é, então, "a imagem que o locutor projeta dele mesmo em seu discurso tal como ela se

\footnotetext{
Minha tradução do francês: "L'importance atribuée à la persone de l'orateur dans l'argumentation est um point essentiel des réthoriques antiques" (AMOSSY, 2010, p. 60).

4 É possível compreender esse gesto nas palavras de Pauliukonis (2008, p. 60). A autora afirma que as categorias da retórica "reapareceram recentemente, principalmente com o desenvolvimento dos estudos relativos à argumentação. A noção de ethos foi, então, retomada e redefinida por alguns pesquisadores da análise do discurso",

${ }^{5} \mathrm{Na}$ retórica, o ethos era concebido apenas através dos textos orais.
} 
inscreve na enunciação mais do que no enunciado, e como ele retrabalha os dados pré-discursivos ${ }^{6 "}$ (AMOSSY, 2010, p. 70). Essa proposta da autora $(2005,2010)$ para compreender a noção é basilar, já que permite entender "como o discurso construiu um ethos baseado em dados pré-discursivos diversos" (AMOSSY, 2010, p. 69)7. Desse modo, "a imagem elaborada pelo locutor se apoia sobre elementos preexistentes, como a ideia que o público faz do locutor antes de sua tomada de palavra, ou a autoridade que lhe conferem sua posição e seu estatuto" (AMOSSY, 2010, p. 69).

No desenvolvimento de sua perspectiva, a autora propõe, em diálogo com a retórica, com os trabalhos de Maingueneau e com a sociologia, pensar o ethos não somente como uma atividade puramente linguageira. Isto é, a noção de ethos permite compreender não apenas o caráter linguístico pelo qual o enunciador constrói a imagem de si, como também a posição social dos sujeitos que tomam a palavra. Desse modo, a imagem prévia do orador bem como a imagem que ele constrói no discurso possuem igual importância em uma tomada de palavra que vise à persuasão. Com isso, a perspectiva do ethos extrapola o funcionamento interno da enunciação. Ela está associada à ordem simbólica da sociedade, ao modo como a sociedade compreende as trocas simbólicas e como os sujeitos se inscrevem nela. Com isso, conforme Amossy (2010, p. 70), a imagem construída pelo sujeito em seu discurso se apoia na ideia que o público faz do locutor antes que ele tome a palavra. Para a autora,

O ethos prévio se elabora sobre a base do papel que o orador ocupa no espaço social (suas funções institucionais, seu estatuto e seu poder), mas também sobre a base da representação coletiva ou do estereótipo que circula sobre sua pessoa. Ele precede a tomada de palavra e a condiciona parcialmente. Ao mesmo tempo, deixa no discurso traços tangíveis que são recuperados tanto pelas marcas linguísticas quanto pela situação de enunciação que constitui a troca ${ }^{8}$.

É preciso compreender, nessa perspectiva, que o ethos na análise da argumentação no discurso é

\footnotetext{
6 Minha tradução do francês: "L'image que le locuteur projette de luimême dans son discours telle qu'elle s'inscrit dans l'enunciation plus encore que dans l'énoncé, et la façon dont il retravaille les donées prédiscoursives" (AMOSSY, 2010, p.70).

7 Minha tradução do francês: "Comment le discurs construit um ethos em se fondant sur des donées prédiscursives diverses" (AMOSSY, 2010, p. 69).

8 Minha tradução do francês: "L'ethos préalable s'elabore sur la base du rôle que remplit l'orateur dans l'espace social (ses fonctions institucionnelles, son statut et son pouvoir), mais aussi sur la base de la représentation collective ou du stéréotype qui circule sur sa persone. Il précéde la prise de parole et la condictionne partiellement. En même temps, il laisse dans le discours des traces tangibles qui sont repéables tantôt dans des marques linguistique, tantôt dans la situation d'enonciation qui est au fondement de l'échange".
}

constituído por um gesto duplo de caracterização. Por um lado, é possível caracterizá-lo em um nível discursivo, conhecido como ethos discursivo, e, por outro lado, em um nível pré-discursivo ${ }^{9}$, conhecido como ethos prévio. Nesse aspecto, o papel do outro - do orador, do público - é fundamental nesse processo, pois é também com base nas imagens que o público construiu previamente sobre o sujeito que a construção da imagem de si do orador irá se basear para que a influência sobre o outro seja eficaz.

A discussão sobre os aspectos discursivo e prévio do ethos também foi fomentada por Maingueneau (2005). Para tal empreendimento, o autor propõe um esquema que, ao relacionar os dois aspectos do ethos, constitui o ethos efetivo e tem como base do esquema os estereótipos. Nesse direcionamento, para que a construção do ethos do enunciador se efetive, o ethos prévio interage com o ethos discursivo. Este último, por sua vez, se desdobra em mais dois aspectos, a saber: o ethos dito, no qual o enunciador apresenta de modo explícito as suas características, e o ethos mostrado, no qual o enunciador, ao invés de afirmar com clareza, deixa marcas recuperáveis na enunciação. A análise dessas marcas é imprescindível na interpretação do ethos e engendra no discurso a dimensão do logos.

\section{Tudo de Blog: articulações sobre o ethos adolescente}

Os sujeitos de linguagem, ao tomarem a palavra, são impelidos por uma série de normas e convenções partilhadas por um grupo que permite que algo seja dito ou não em um espaço de encenação. Essas normas "resultam de uma interação das trocas comunicacionais do cotidiano, regulação que acaba instaurando práticas nas quais os membros de uma mesma comunidade cultural se reconhecem" (CHARAUDEAU, 2012, p. 2). O reconhecimento entre os membros está sujeito a alterações de acordo com a identidade dos sujeitos envolvidos na troca e com o contexto histórico que determina as modificações das práticas e das representações sociais (CHARAUDEAU, 2012).

No que tange a este trabalho, esse espaço de trocas, resultado da interação e regulação de normas e práticas mais ou menos estáveis, é a seção Tudo de Blog. É nela que as adolescentes interagem numa relação de reconhecimento que permite que algo possa ser dito nesse espaço no qual as práticas da adolescência vão sendo ensaiadas e atualizadas de acordo com as representações sociais. A seção é, pois, um dispositivo de encenação no

\footnotetext{
9 Vale ressaltar que pré-discursivo compreende um momento anterior à enunciação e não a algo que está fora do discurso.
} 
qual se estabelece um contrato de comunicação ${ }^{10}$ que tem como base uma situação de comunicação ${ }^{11}$ estabelecida.

No $T D B$, é a situação de comunicação que legitima o dizer das adolescentes e, ao serem escolhidas pela Capricho para discutir sobre os temas, a identidade social desses sujeitos, enquanto adolescentes colunistas da revista, legitima seu direito à palavra, influenciando no que pode e deve ser dito na seção e nas imagens de si construídas pelas adolescentes. Nesse sentido, na construção da imagem de si, é tomado como referência o estatuto dos sujeitos e ainda a sua posição social. Essas imagens que o público constrói se apoiam em certas representações sociais que circulam no imaginário adolescente da revista.

A noção de representação social é produtiva, uma vez que permite refletir sobre o modo como "todo ato de comunicação, sendo um ato de troca entre dois ou mais parceiros, cria um elo social que parte de normas de comportamentos e estabelece representações necessariamente partilhadas" (CHARAUDEAU, 2008a, p. 195). As representações, então, são constituídas por um "conjunto de crenças, dos conhecimentos e das opiniões produzidas e partilhadas pelos indivíduos de um mesmo grupo a respeito de um dado objeto social" (CHARAUDEAU, 2008a, p. 196).

Nesse sentido, o Tudo de Blog se configura como um lócus no qual as adolescentes estabelecem as "práticas sociais" no âmbito midiático, produzindo e partilhando crenças, conhecimentos e opiniões sobre um dado objeto social, tematizado pela revista, atribuindo-lhe valores, sustentados por um sistema de valores e crenças que recobrem as afinidades dos parceiros da troca. Ao mesmo tempo, na seção, cria-se um "elo social" regido por normas de comportamentos, partilhando representações da adolescência. Esse conjunto de representações partilhado, afirma Lima (2006, p.141), mantém estreita relação com os imaginários sociais.

Vale, então, considerar que o ethos se relaciona aos imaginários sociais e se nutre dos estereótipos de sua época. A noção de estereótipo é fundamental para essa questão, visto que é sobre ela que a construção de uma

\footnotetext{
${ }^{10}$ A noção de contrato de comunicação é importante, visto que ela permite compreender os espaços de liberdade e restrições que constituem as trocas dos sujeitos. Essa noção "pressupõe que os indivíduos pertencentes a um mesmo corpo de práticas sociais estejam suscetíveis de chegar a um acordo sobre as representações linguageiras dessas práticas" (CHARAUDEU, 2008, p.56). Essa perspectiva é importante neste trabalho, pois, além de permitir compreender as regras que estão em jogo na encenação do Tudo de Blog, permite ainda analisar a construção da imagem que o sujeito enunciador projeta de si mesmo nesse espaço.

${ }^{11}$ Numa perspectiva discursiva, essa noção, intimamente ligada à de contrato, permite compreender o ambiente físico e social do ato de comunicação, ou seja, a situação "é externa ao ato de linguagem, embora constitua as condições de realização desse ato" (CHARAUDEAU, 2008, p.69). A situação de comunicação constitui um espaço de troca no qual todo sujeito falante se relaciona com os parceiros.
}

imagem de si se funda. Sobre a estereotipagem, vale pontuar que Amossy $(2005$, p. 125) a considera como uma "operação que consiste em pensar o real por meio de uma representação cultural preexistente, um esquema coletivo cristalizado". Sendo assim, o ethos construído pelas adolescentes no TDB é nutrido pelos conhecimentos e crenças dos leitores sobre as adolescentes e, mais especificamente, sobre as adolescentes que escrevem para a revista. No que tange ao ethos das escreventes, são os valores que circulam entre os leitores, os quais são recobertos pelo imaginário, que influenciam na construção de uma imagem (positiva) de si.

Uma questão que irrompe dessa relação do ethos com a percepção das representações sociais é a possibilidade de compreender a construção de imagens não apenas ligada a sujeitos individuais, mas também ampliar a noção de ethos e pensá-lo numa abrangência coletiva. É, nesse sentido, que se pode afirmar que existe um ethos da adolescência feminina na Capricho. Adoto, então, a perspectiva de Charaudeau (2008, p. 117), ao afirmar que "na medida em que o ethos está relacionado à percepção das representações sociais que tendem a essencializar essa visão, ele pode dizer respeito tanto a indivíduos quanto a grupos".

Para o autor (2008), os indivíduos do grupo partilham com os outros indivíduos desse mesmo grupo caracteres similares, que, quando vistos de fora, causam a impressão de que esse grupo representa uma entidade homogênea. Com base nessa afirmação, é possível entender que os sujeitos adolescentes consumidores da Capricho partilham entre si modos, estilos, costumes semelhantes que configuram a ilusão de uma homogeneidade da adolescência feminina e, por sua vez, interditam outros dizeres sobre a mulher na adolescência. Na esteira dessa discussão, Kerbrat-Orecchioni (2010) caracteriza dois tipos de ethé. O primeiro ligado ao indivíduo que, ao tomar a palavra, será levado a interagir com outros indivíduos, e o segundo ligado a uma coleção de indivíduos que partilham das mesmas normas comunicativas.

A caracterização da autora (2010) permite refletir sobre o modo como o ethos individual incide sobre o ethos coletivo e vice-versa. No $T D B$ e, por consequência, na Capricho, o ethos construído pelas adolescentes se vale dos valores que circundam o ethos da adolescência feminina no imaginário da revista que, por sua vez, é apreendido pelo comportamento similar das adolescentes que validam e partilham de certos valores.

Nessa perspectiva, é importante compreender que a construção, assim como a interpretação do ethos, relaciona-se a uma problemática discursiva na qual podem ser recuperados diferentes modos de apreensão, devido ao caráter polissêmico que o termo adquiriu. Ressaltei a importância do ethos para a construção do ethos discursivo 
prévio (quer seja ele dito ou ethos mostrado), bem como ressalto a importância do ethos coletivo.

Refletir sobre a polissemia do ethos e sua importância para análise argumentativa requer ainda compreendê-lo em sua relação com o pathos e o logos. Nesse sentido, o que é "preciso reter inicialmente aqui é o fato de que o logos convence em si e por si mesmo, independentemente da situação de comunicação concreta", afirma Eggs (2005, p. 41). Ao contrário, continua o autor, "o ethos e o pathos estão sempre ligados à problemática específica de uma situação e, sobretudo, aos indivíduos concretos nela implicados" (EGGS, 2005, p.41). As dimensões argumentativas do logos e do pathos relacionam-se de modo direto com o ethos, pois na construção da imagem de si o sujeito põe em cena essas dimensões.

Recorrer à dimensão do logos na análise da argumentação implica compreender a estrutura linguísticodiscursiva do discurso em $s i$ e todos os seus componentes (GALLINARI, 2011). Nesse sentido, ao apresentar um ponto de vista, o sujeito se vale dos mecanismos de estrutura da língua para persuadir. Por outro lado, "os recursos de patemização" (LIMA, 2006) são igualmente fundamentais para a eficácia da persuasão e aliados ao ethos e ao logos são indispensáveis para a eficácia argumentativa.

Acredito que tais recursos são extremamente importantes e, talvez, até mesmo fundamentais no processo de persuasão desencadeado pelos sujeitos em seus discursos produzidos no $T D B$, uma vez que, aliados à construção de imagens e à apresentação das provas demonstrativas, podem mobilizar o leitor de modo mais eficaz.

Vale ressaltar que o modo como as escreventes defendem seu ponto de vista diante do objeto tematizado pela Capricho é um constructo de uma rede de verossimilhança por meio do qual se quer atingir a instância de recepção: os leitores. Esse jogo tem como base a construção das imagens das adolescentes em sua articulação com os efeitos de emoção e as escolhas realizadas para construir os enunciados.

Nesse investimento, tomo como direcionamento que compreender a relação da tríade ethos, logos e pathos como base da argumentação é perceber que esta funciona numa perspectiva tridimensional (LIMA, 2006). A incursão no campo argumentativo se dá, principalmente, pelo viés da análise do ethos, noção fundamental para o desenvolvimento deste artigo, assim como pelas relações estabelecidas entre essa prova e o pathos e o logos, o que me possibilitará compreender o funcionamento argumentativo do discurso no Tudo de Blog.

\section{"Estar na moda" com Capricho}

Volto o olhar para os dizeres das escreventes no $T D B$, a fim de observar as imagens de si que são construídas nesses espaços. Nesse percurso, compreendo que é a experiência de vida, ou mesmo as práticas individuais do sujeito adolescente, que fazem emergir na enunciação um efeito intimista, pondo em evidência o fio da argumentação. São, no entanto, os domínios de competência dos sujeitos de linguagem, através da encenação do eu, que permitem que as adolescentes performatizem as figurações de gênero e, assim, construam uma imagem de si.

O assunto da beleza atravessa os indivíduos, levando a corporeidade a ocupar bastante espaço no debate midiático. É possível recuperar por meio das representações sociais em torno do feminino que os sentidos de beleza, no que tange à construção social dos sujeitos, afetam de modo diferenciado e contundente as imagens de mulher. A construção do corpo feminino adolescente estampa a capa e as páginas da revista, abordando as diversas dimensões e características que constituem a normatização do corpo da mulher na adolescência. Nesse sentido, a dinâmica da beleza é atravessada e (re)significada por diversos gestos que circundam o universo adolescente.

No $T D B$, a recorrência a essa temática não poderia estar ausente, visto que a seção se centra sobre as narrativas de vida adolescente. Nesse sentido, explorar as experiências de vida feminina visa compartilhar um conhecimento baseado na verdade, na vida como ela é. É a recorrente presença desse tema na revista que faz com que este assunto seja o primeiro gesto de análise da construção das imagens de si adolescente. Para tanto, recorto a seção que aborda a seguinte temática: Com glamour: nossos blogueiros dizem se é preciso estar na moda para ser chique. Considero que a temática faz parte do universo da beleza e, como tal, uma possibilidade de normatização dos corpos femininos.

O corpo, moldado enquanto prática sócio-histórica (LE BRETON, 2010), é um dispositivo da moda, na medida em que certos modelos corporais, baseados, na sociedade contemporânea, num corpo magro, formam uma tendência. Nesse sentido, a forma física é associada a outros elementos corporais que compõem o quadro da beleza. Ao corpo belo e magro, associa-se o cuidado com outros elementos que compõem o conjunto do corpo, como o cuidado com o cabelo, as unhas, a maquiagem e os modos de vestir.

A construção da beleza na adolescência se dá não apenas por essa construção corporal, mas também por uma construção psicológica da personalidade, da estética do belo e do feio. O discurso da moda atravessa substancialmente essa construção. No universo Capricho, a moda também é um elemento de beleza, mas se expande como uma forma de busca por um estilo próprio. Dessa 
forma, é possível pensar não apenas no corpo da moda, mas na moda que está no corpo. É preciso compreender, então, que os elementos da moda constituem a estética do belo e do feio e passam pela construção do corpo e da sociabilidade adolescente.

Nesse sentido, a forma como o corpo é moldado se dá também pelos modos de se vestir do adolescente. Assim, a maneira de vestir-se permite a identificação dos indivíduos como filiados a determinados grupos. É possível, então, identificar-se com esta ou aquela tendência, com este ou aquele grupo pelas escolhas de roupa, sapato, estilos de música. Assim, na adolescência, formam-se os grupos por essas identificações, o que permite, então, a normatização do grupo das ditas patricinhas, de nerds, de rockeiros, de skatistas, de nemos, entre outros.

Beleza, saúde e moda são, na agenda adolescente, pautas que determinam o estilo de vida dos sujeitos. A moda, sobretudo, é responsável pela identificação identitária dos grupos juvenis, visto que determina os estilos e gostos que fazem com que os indivíduos de um grupo compartilhem ou não os mesmos interesses e, com isso, formem subgrupos que determinam os estilos da adolescência. Como apontou Freire Filho (2006), a presença do estilo sempre esteve presente na construção da Capricho como forma de construção da identidade adolescente. Desse modo, é preciso que o adolescente construa um estilo que seja aparentemente próprio, resultado do individualismo contemporâneo, para que ele possa integrar-se ao grupo.

Há, na revista, uma recorrência em construir a imagem da adolescência ligada à moda. É, nesse contexto, "que se fala de 'tribos urbanas', ou seja, grupo de jovens que se identificam por adotarem modismos comuns, sendo cada um desses grupos caracterizado por seu perfil específico de consumo de determinados bens" (CATANI; GILIOLI, 2008, p. 25). Para esses autores, a moda adolescente seria, em essência, um conjunto de expressões (música, roupa, adereços, postura, comportamento), "modos de viver e estilo que cada um desses grupos de jovens adota para se diferenciar dos outros e afirmar certos valores sociais e culturais" (CATANI; GILIOLI, 2008, p. 25).

No estudo sobre moda realizado por Calanca (2008, p. 11), compreende-se com o termo moda "o fenômeno social da mudança cíclica dos costumes e dos hábitos, das escolhas e dos gostos, coletivamente validado e tornado quase obrigatório". Para a autora, o termo "costume" mantém uma relação estreita com a noção de moda, já que é possível compreender tal termo na acepção de "hábito constante e permanente que determina o comportamento, a conduta, o modo de ser" de uma comunidade e de um grupo social. A noção de costume remete ainda ao conceito de sistema, de estrutura, ou seja, a um conjunto de vários elementos relacionados entre si. Esses elementos, considerados isoladamente, são privados de valor, assumindo um significado apenas no momento em que são ligados por um conjunto de normas e regras coletivas. Desse ponto de vista, conclui a autora, "a moda é sempre um fenômeno de costume" (CALANCA, 2008, p. 12).

A estética da beleza está associada ao estilo de determinado grupo. Vale ressaltar que essas escolhas não são homogêneas e não obedecem a regularidades estanques. Nesse sentido, elementos que tendem a caracterizar determinados grupos vão sendo captados por outros grupos, de acordo com as tendências da moda. Além disso, os adolescentes que se identificam com determinados grupos podem ser inseridos em outros, constituindo outras identidades.

Essa constatação permite-me compreender, de acordo com Charaudeau (2009), o princípio de alteridade na constituição da identidade psico-social do sujeito. Para o autor $(2009, \mathrm{n} / \mathrm{p}$.), segundo esse princípio, “cada um dos parceiros da troca está engajado num processo recíproco (mas não simétrico) de reconhecimento do outro e de diferenciação para com o outro, cada um se legitimando e legitimando o outro através de uma espécie de 'olhar avaliador"'. É esse olhar, confirma o autor, que permite afirmar que a identidade se constrói através de um cruzamento de olhares: "existe o outro e existo eu, e é do outro que recebo o eu" (CHARAUDEAU, 2009). Retomo, segundo o autor, a importância das identidades na construção do ethos. Nas palavras do autor (2008, p. 115):

O sujeito aparece, portanto, ao olhar do outro, com uma identidade psicológica e social que lhe é atribuída, e, ao mesmo tempo, mostra-se mediante a identidade discursiva que ele constrói para si. O sentido veiculado por nossas palavras depende ao mesmo tempo daquilo que somos e daquilo que dizemos. O ethos é o resultado dessa dupla identidade, mas ele termina por se fundir em uma única.

Nesse sentido, a construção da identidade adolescente por meio da moda e, por consequência, do estilo implica a construção de um ethos. Conforme Garcia (2005, p. 61), "para além da persuasão comportamental, as novidades que rebuscam estilo e elegância visual na moda realizam uma combinação direta entre corpo e vestuário, provocando um enunciado cada vez mais complacente com os entornos de consumo, identidade, diversidade e diferença". Retomando a construção das imagens de si no $T D B$, trago para a análise a seguinte discussão da seção: 


\section{Quadro-dizer da seção Tudo de blog}

\begin{tabular}{|l|l|}
\hline \multicolumn{1}{|c|}{ Tudo de blog } \\
\hline $\begin{array}{l}\text { Com glamour } \\
\text { Nossos blogueiros dizem se é preciso estar na moda para ser chique }\end{array}$ \\
\hline $\begin{array}{l}\text { Nome: Thais Aragão } \\
\text { Idade: } 20 \text { anos }\end{array}$ & $\begin{array}{l}\text { A MODA É UMA ESCOLA } \\
\text { Eu amo a moda, mas acho que ela não me ama. Toda vez que penso em comprar os itens maravilhosos } \\
\text { que me são apresentados, olho na carteira e vejo que não é possível. Se a moda me amasse, seria mais } \\
\text { acessível e tudo o que está em alta ficaria ótimo no meu corpo! O que fazer, então? Entendê-la. Eu, que } \\
\text { estudei por 3 anos essa indústria, posso dizer que a moda realmente te induz ao consumo desesperado } \\
\text { pelo desejo de ser desejado. Afinal, quem não tem uma invejinha das irmãs Olsen, que estão sempre } \\
\text { bem-vestidas? Por outro lado, a moda te força a olhar e pensar. Ela te ajuda a descobrir o seu estilo } \\
\text { quando você coloca um vestido godê ou evasê e vê qual deles fica melhor. E, no final, você sempre } \\
\text { consegue dar seu toque pessoal. Isso se chama estilo. Se você tem estilo, tem personalidade. } \\
\text { E personalidade é a chave para ser chique. }\end{array}$ \\
\hline
\end{tabular}

subquadro I

\begin{tabular}{|l|l|}
\hline $\begin{array}{l}\text { Nome: Rodrigo Gurgel } \\
\text { Idade: } 15 \text { anos }\end{array}$ & $\begin{array}{l}\text { CIVILIZE-ME } \\
\text { Tenho o direito de usar chinelo, short e regata para andar pelo meu bairro e não destratado por isso. }\end{array}$ \\
$\begin{array}{l}\text { Tenho o direito de pedir informação em uma loja de roupa de festa, vestido assim, sem que a vendedora } \\
\text { me lance aquele olhar de análise da cabeça aos pés e solte um "não" com a entonação bem conhecida } \\
\text { de "dê o fora daqui". Cada um tem o direito de usar o que quiser. Parte do processo de estar chique é } \\
\text { se sentir chique. Parte do processo de estar bonito é sentir-se bonito. Porque não existe maquiagem no } \\
\text { mundo que tenha o mesmo efeito que autoconfiança. Ser chique está no olhar, nos gestos, na mente, } \\
\text { no falar. A roupa é o menos importante. Eu vou continuar usando bermuda e chinelo para andar no meu } \\
\text { bairro porque tenho direito a isso, quer a dona da loja, goste ou não. Verdade seja dita: há algo mais } \\
\text { confortável do que ser quem a gente é? }\end{array}$ \\
\end{tabular}

subquadro II

Nome: Louise Mira

Idade: 17 anos

\begin{abstract}
SE A MODA PEGA...
E se meu salto 15 quebrar? E se meu gloss escorrer? E se a estampa não combinar? E se o meu tom destoar? E se a etiqueta cair? E se o preço subir? E se a saia encurtar? E se a meia rasgar? E se a moda pegar? O modismo é o prefácio da mesmice. A personalidade de alguém não pode ser vendida numa estampa ou numa etiqueta. A identidade não vem escrita numa logomarca e nem todos seguem à risca a trilha da passarela. O "último grito da moda" nem sempre expressa a real beleza. Roupas, grifes e maquiagens são atraentes, mas não são um sinal obrigatório de elegância, bom gosto ou personalidade. Quem realmente tem estilo não fica de olhos grudados nas notícias de moda, nem se veste ou se porta de acordo com um way of life enlatado, nem se sente um criminoso se, simplesmente, cria as próprias regras do jogo da moda. Crime maior é ser vitima do sistema fashion.
\end{abstract}

Ao discorrer sobre as estratégias que o enunciador se vale na construção de um ethos, Maingueneau afirma que o mesmo pode ser atribuído por meio de um modo explícito de falar de si. Nesse sentido, o enunciado que inicia o dizer do subquadro I, nessa cena, é uma espécie de confissão do sentimento e, ao mesmo tempo do ethos dito, da enunciadora. É por meio do que ela diz sobre a sua relação de amor e rejeição pela moda que a escrevente constrói a sua imagem e expressa seu sentimento.

De acordo com Plantin (2010, p. 57), "se tomarmos como ponto de partida o dado linguístico, entraria em questão explicar a orientação explícita de um discurso em direção à expressão de uma emoção". Desse modo, conforme afirma o autor, seria possível argumentar emoções. Nas palavras do autor (2010, p.58), "há argumentação de uma emoção quando o discurso justifica a atribuição de um experienciado a uma pessoa". Ao enunciar "eu amo a moda, mas acho que ela não me ama", há a argumentação de uma emoção na medida em que a enunciadora expressa o sentimento de amar. Vale ressaltar, contudo, que não há instrumentos para o analista avaliar se a emoção expressa pelo enunciador seja a realmente sentida pelo sujeito comunicante, conforme pontuou Lima (2011).

Apontei um dos elementos para análise da emoção na proposta de Plantin (2010). Gostaria de apontar, por meio desse enunciado, outra técnica, a saber: a designação direta da emoção. Nela, a emoção é claramente designada por um termo de emoção, no caso o verbo amar. É preciso chamar atenção para a inversão, introduzida pelo operador argumentativo mas, que desloca as posições do sujeito que experiencia a emoção da posição gramatical 
de sujeito para a posição de objeto direto. A inversão sintática evidencia o deslocamento de sentido no qual há a pressuposição, caracterizados pelo verbo achar, de que o objeto amado rejeita o ser desejante.

Constrói-se, por meio da emoção, a imagem de si como rejeitada pela moda. Essa imagem, no entanto, é reforçada, ao longo da enunciação, ao ser associada ao consumismo e ao corpo. Essa associação entre moda e consumo, na afirmação de Garcia (2005, p. 68), "responde ao chamado do mercado, uma vez que as ações humanas compreendem a diversidade de situações discursivas, capaz de deslocar e valorizar a aproximação estratégica do corpo/mercado". Para a autora (2005, p. 68), "essa aproximação, recorrente na moda, combina as predições do vestuário aos valores de bens materiais e simbólicos".

Essa relação corpo/mercado é apresentada na enunciação da escrevente na medida em que ela recupera representações da moda como algo inacessível ao bolso e ao corpo, já que o consumo desenfreado pelos bens que a moda impõe não são acessíveis à vida econômica do adolescente e também ao afirmar que a indústria da moda produz roupas que não cabem nos corpos "reais". Instaura-se, então, um argumento de autoridade, "eu, que estudei por 3 anos essa indústria, posso dizer que a moda realmente te induz ao consumo desesperado pelo desejo de ser desejado", que legitima a constatação da enunciadora. A construção desse argumento pode ser compreendida em termos silogísticos ${ }^{12}$ : aquelas que estudam moda têm autoridade para falar sobre como a moda induz o consumo; eu estudei moda, logo tenho autoridade para falar sobre isso.

$\mathrm{O}$ recurso do argumento fundado na autoridade auxilia na construção da imagem da escrevente à medida que reforça a imagem de amante da moda por meio do conhecimento formal sobre o funcionamento da indústria. Além de construir a imagem de si, a escrevente constrói também a imagem do outro. Nesse caso, a imagem das irmãs Oslen (gêmeas famosas pelos trabalhos que faziam quando crianças e ícones da moda) por meio do questionamento "afinal, quem não tem uma invejinha das irmãs Olsen?" convoca o leitor a participar do mundo ético da escrevente, dividindo com ele a responsabilidade de sentir inveja. $\mathrm{O}$ enunciado se inscreve em uma representação positiva da inveja na qual reforça a ideia de que as mulheres sentem inveja umas das outras.

\footnotetext{
${ }^{12}$ Argumentar, esclarece Plantin (2008: 15), "é ligar proposições, constituir um discurso coerente, baseado num elemento considerado como evidente (para os sentidos, para a intuição intelectual ou moral), e dele derivar uma proposição segunda menos segura. É apoiar uma afirmação - a conclusão - sobre uma boa razão - o argumento". Isso faz emergir no discurso a possibilidade de construir os argumentos por meio do silogismo, o qual está ligado ao pólo das boas razões e é um argumento lógico (os A são B, isto é um A, logo isto é um B).
}

A relação entre moda e estilo também é retomada na fala da escrevente. A moda, nessa enunciação, é apresentada como a possibilidade de a adolescente descobrir o seu estilo e, assim, poder construir sua personalidade. Instaura-se, nessa enunciação, a capacidade que a moda possui de construir o estilo e a personalidade adolescente. Uma forma delicada de pensar o corpo contemporâneo é observar os caminhos da moda e do estilo, assevera Garcia (2005). Nesse sentido, a fala da adolescente orquestra o discurso da moda para o qual o vestuário compõe o corpo, dando-lhe continuidade.

Numa outra direção, o subquadro II instaura uma enunciação de reivindicação. Sobre esse quadro, gostaria de chamar a atenção, pois ele configura uma escrita masculina. Ter um adolescente escrevente de uma seção da revista Capricho que possui uma presença predominante de meninas chama atenção pelo fato de não ser uma prática corrente na revista. A presença dos meninos na revista, de modo geral, aparece em seções específicas nas quais se dá apenas a voz dos meninos, seja para expor seus gostos pessoais, sua personalidade, o que mais gostam entre as meninas ou mesmo as suas experiências de vida. Como é o caso da seção Entre eles que simula um bate-papo entre três garotos a partir de uma pergunta da revista.

Nesse sentido, ao ter direito à palavra numa seção marcada pela presença das adolescentes, o enunciador constrói uma imagem de si ligada à reivindicação. A argumentação se funda pela repetição estrutural, com variação, da expressão tenho direito/ tem direito. A repetição, afirma Marcuschi (1992), é uma estratégia de coesão que tem como uma das funções o efeito de ênfase. A repetição, nessa enunciação, se dá, então, pela ênfase em apresentar o sujeito como um ser de direito, que, como tal, deve ter seu direito assegurado.

Essa reivindicação pauta-se em estereótipos de valores morais que recobrem a prática da sociabilidade. Para tanto, a repetição permite a partilha do conhecimento de que o que está sendo reivindicado é a manutenção de um direito já conquistado, que é o direito constitucional à liberdade que, por sua vez, engendra o direito de ir e de vir. No caso do texto, poder ir e vir a qualquer lugar vestido do modo como desejar. A escolha desse texto pela Capricho pode ser compreendida, visto que se levam em consideração os pressupostos partilhados de uma mobilização feminina pelo direito de ir e vir vestindo o que quiser.

O que deve ser levado em consideração, no entanto, é a inscrição sócio-histórica do sujeito que, ao ser inscrita na doxa, caracteriza a experiência masculina numa construção diferente da feminina. Nesse sentido, os itens lexicais selecionados pelo enunciador remetem ao universo do direito por meio do qual se estabelecem 
relações discursivas que permitem a leitura de um ethos ligado a uma dimensão mais lógica, racional, reforçando, assim, a imagem masculina associada ao raciocínio, enquanto a imagem feminina está mais associada à passionalidade. O recurso à reivindicação é apresentado, então, como um direito do cidadão e uma forma de civilidade, o que pode ser confirmado pelo título civilize-me. Ao mesmo tempo a construção do título parece um pouco discordante em relação à imagem de reivindicante construída no enunciado, por meio da enunciação, já que apresenta a imagem de um adolescente não civilizado. É possível recuperar, então, na totalidade da enunciação, que civilize-me também apresenta um tom de reivindicação, mas recobre o imaginário de que pelo fato de não se vestir de modo adequado, conforme os lugares que frequenta, o adolescente é tido, no olhar do outro, como não civilizado. Daí a reivindicação: civilize-me.

Interessante observar, nesse gesto, o modo como o adolescente constrói, pela recusa, a imagem que ele acredita que o outro tem dele. Na organização da narrativa, esse olhar do outro aparece na presença da personagem (a vendedora) numa localização no espaço fechado (a loja) por meio do qual a vendedora lança ao enunciador um olhar de reprovação pelas vestimentas que ele usa. É essa reprovação que engendra no discurso o ethos prévio do enunciador como não civilizado. Nesse sentido, ele recusa essa imagem, construindo um ethos de sujeito de direito, logo um cidadão. Assim, vestir-se de acordo com padrões da moda estabelece uma fronteira na relação do sujeito com o corpo nas suas práticas de cidadania.

No subquadro III, o recurso da repetição na progressão do texto é utilizado novamente como estratégia de encadeamento argumentativo. Além da função de ênfase, nota-se ainda o recurso sendo utilizado como efeito estilístico da narração. A repetição introduz, no texto, as preocupações, tidas cotidianas, da mulher com o universo da moda. Esse efeito estilístico enfatiza, então, a recorrência das inquietações femininas nos assuntos de beleza. A construção dos questionamentos (introduzidas pela oração subordinada condicional, sendo o $e$ um uso estilístico com a função de reforço), apagando a oração principal convoca o leitor a ativar as possíveis frases que poderiam ocupar o espaço vazio. Entre elas, "o que eu vou fazer?" seria uma possibilidade. Assim, uma possibilidade de construção seria: "e se meu salto 15 quebrar, o que eu vou fazer?". O preenchimento da categoria vazia, no entanto, fica por conta do leitor que seleciona, por meio das representações sociais, as possibilidades de construções que comporiam a frase.

Esse efeito da repetição como preocupação cotidiana da mulher com os elementos de beleza pode ser confirmada no enunciado que segue os questionamentos, "o modismo é o prefácio da mesmice". Gostaria de chamar a atenção, nesse texto, para o efeito de objetividade da enunciação. Após as perguntas, a progressão do texto se dá por meio das frases afirmativas nas quais a impessoalidade é a marca da enunciação. Nesse sentido, o texto busca o apagamento do sujeito a fim de conferir mais credibilidade à enunciação. No entanto, o sujeito deixa escapar a sua subjetividade ao se inscrever no discurso "e se meu salto 15 quebrar?" "e se meu gloss escorrer?" "e se meu tom destoar?". Essas estratégias engendram uma imagem adolescente como despreocupada com a beleza. Para parecer credível, entretanto, a enunciadora se vale da impessoalidade, embora deixe escapar sua subjetividade.

As imagens de si recuperadas na enunciação adolescente que possuem como tema o cuidado de si revelam que a construção sócio-histórica dos sujeitos afeta a construção da sua imagem, permitindo que se recuperem apenas determinadas imagens em torno do feminino, silenciando outras. Escrever sobre si, contando sua vida, sua experiência, engendra um ethos no qual o efeito intimista delineia uma proximidade com o leitor.

O discurso da seção se inscreve, então, numa polêmica, assim como a seção anterior, visto que apresenta posicionamentos semanticamente contrários, ainda que estabeleçam relações, frente ao objeto tematizado. O $T D B$, enquanto um espaço discursivo, ao se valer de posicionamentos diferentes a cada publicação, pode ser entendido como uma espécie de processo de interincompreensão generalizada, conforme apresenta Maingueneau (2008, p. 99), devido à sua própria condição de possibilidade de apresentar posições enunciativas contrárias entre si.

\section{Considerações finais}

O discurso midiático, sobretudo aquele veiculado pelas revistas femininas, engendra diversas representações da imagem da mulher na sociedade. Essas representações são recuperadas no e pelo discurso e recobrem os dizeres e os modos de dizer do sujeito mulher. Nesse sentido, apenas por meio do contrato comunicacional, nos diria Charaudeau, e por meio de uma inscrição na doxa, nos diria Amossy, seria possível o reconhecimento das representações das práticas sociais dos sujeitos. É nesse quadro de reconhecimento que o sujeito, ao enunciar, se vale de determinadas estratégias que viabilizam a produção de determinados efeitos sobre o outro. Nesse jogo de agir sobre o outro é que desvelar o funcionamento argumentativo que recobre todo e qualquer discurso em torno da mulher foi e é um caminho eficaz para revelar as imagens de si na seção Tudo de Blog e, assim, as representações de mulher no imaginário adolescente.

Vale compreender que a produção de discursos tem história e memória recuperadas na construção 
argumentativa, por meio da relação entre a doxa e a memória. Nesse sentido, nas palavras de Amossy (2010, p.92), "o conhecimento disso que é pensado e dito numa época passada é necessário para a boa compreensão de um discurso argumentativo". É nessa perspectiva que este trabalho se delineou como um gesto de interpretação, pelo funcionamento argumentativo dos discursos, do modo como, por meio do dizer adolescente, a construção de certas imagens sobre a mulher adolescente foram recuperadas pela memória e atualizadas na história.

O gesto analítico permitiu compreender como, por meio da enunciação, as enunciadoras deixam, na materialidade do texto, marcas, pistas que evidenciam a relação entre ethos, logos e pathos, noções fundamentais para a argumentação no discurso. Posso dizer, então, que a análise das imagens de si e do outro puderam revelar, além do caráter da emoção, o cuidado de si que perpassa a enunciação, expondo imagens comumente recuperáveis nos dizeres sobre a adolescência feminina. Pude perceber, assim, que, em cada enunciação específica, as imagens de si revelam uma preocupação com o corpo e a imagem, recobertos pelo discurso da moda. Com efeito, pude desvelar com este trabalho que as imagens de si das adolescentes estão apoiadas em uma herança sociocultural construída em relação à mulher.

\section{Referências}

AMOSSY, Ruth (Org.). Imagens de si no discurso: a construção do ethos. Tradução Dilson Ferreira da Cruz et al. São Paulo: Contexto, 2005.

AMOSSY, Ruth. L'argumentation dans le discours. 3. ed. Paris: Armand Colin, 2010.

CALANCA, Daniela. História social da moda. Tradução Renato Ambrosio. São Paulo: SENAC, 2008.

CATANI, Afrânio Mendes; GILIOLI, Renato de Souza Porto. Culturas juvenis: múltiplos olhares. São Paulo: UNESP, 2008.

CHARAUDEAU, Patrick. Linguagem e discurso: modos de organização. Tradução Aparecida Pauliukonis e Ida Lúcia Machado. São Paulo: Contexto, 2008.

CHARAUDEAU, Patrick. Discurso político. Tradução Dilson Cruz e Fabiana Komesu. São Paulo: Contexto, 2008a.

CHARAUDEAU, Patrick. Identidade social e identidade discursiva, o fundamento da competência comunicacional. In: PIETROLUONGO, M. (Org.). O trabalho da tradução. Rio de Janeiro: Contra Capa, 2009. p. 309-326. Disponível em: <http:// www.patrick- charaudeau.com/Identidade-social-e-identidade. html>. Acesso em: jun 2012.
EGGS, Ekkehard. Ethos Aristotélico, Convicção e Pragmática Moderna. In: AMOSSY, Ruth (Org.). Imagens de si no discurso: a Construção do Ethos. São Paulo: Contexto, 200. p. 29-56.

FREIRE FILHO, João. Em cartaz, as garotas superpoderosas: a construção discursiva da adolescência feminina na revista Capricho. Revista Fronteiras: estudos midiáticos, n. 8, p.102111, 2006. Disponível em: <http://revcom.portcom.intercom. org.br/index.php/fronteiras/article/view/3142/2952>. Acesso em: 15 set. 2009.

GALINARI, Melliandro Mendes. A polissemia do logos e a argumentação: contribuições sofísticas para a Análise do Discurso. EID\&A - Revista Eletrônica de Estudos Integrados em Discurso e Argumentação, Ilhéus, n. 1, p. 93-103, nov. 2011.

GARCIA, Carol. MIRANDA, Ana Paula. Moda é Comunicação. São Paulo: Anhembi Morumbi, 2005.

KERBRAT-ORECCHIONI, Catherine. O ethos em todos os seus estados. In: MACHADO, I.; MELLO, R. (Org.). Análises do discurso hoje. Rio de Janeiro: Nova fronteira/Lucerna, 2010. v. 3. p. 117-136.

LE BRETON, David. A sociologia do corpo. 4. ed. Rio de Janeiro: Vozes, 2010

LIMA, Helcira Maria. Na tessitura do processo penal: a argumentação no Tribunal do Júri. Tese (Doutorado) - Programa de Pós-Graduação em Estudos Linguísticos, Universidade Federal de Minas Gerais, Belo Horizonte, 2006.

MAINGUENEAU, Dominique. Novas tendências em análise do discurso. Tradução Freda Indursky. 3. ed. Campinas: Pontes, 1997.

MAINGUENEAU, Dominique. Ethos, cenografia, incorporação. In: AMOSSY, R. (Org.). Imagens de si no discurso: a construção do ethos. São Paulo: Contexto, 2005. p. 69-91.

MAINGUENEAU, Dominique. Polifonia e cena da enunciação na pregação religiosa. In: EMEDIATO, W.; LARA, G. M. P.; MACHADO, I. L. (Org.). Análises do discurso hoje. Rio de Janeiro: Nova Fronteira, 2008. v. 1.

MARCUSCHI, Luiz Antônio. A repetição na língua falada: formas e funções. Tese (Título de professor titular) Departamento de Letras da Universidade Federal de Pernambuco. Recife, 1992.

PLANTIN, Christian. As razões das emoções. Tradução Emília Mendes. In: MENDES, Emília; MACHADO, Ida Lúcia (Org.). As emoções no discurso. Campinas: Mercado de Letras, 2010. v. II. p. 57-80.

SOUZA, Luana Ferreira. O efeito intimista na escrita sobre si: olhares para a construção da imagem adolescente com Capricho. Dissertação (Mestrado) - Faculdade de Letras, Universidade Federal de Minas Gerais, 2013.

Recebido: $16 / 05 / 2018$

Aprovado: 02/08/2018

(D) LUANA FERREIRA DE SOUZA <luanafesouza@gmail.com>

Doutoranda, Universidade Estadual de Campinas, Campinas, São Paulo, Brasil. 